\title{
Aerodynamic Assessment of Young Women's Voices as a Function of Oral Contraceptive Use
}

\author{
Mary Gorham-Rowan Linda Fowler \\ Department of Communication Disorders, Florida State University, Tallahassee, Fla., USA
}

\section{Key Words \\ Voice, aerodynamic assessment · Oral contraceptive}

\begin{abstract}
Objective: To examine possible differences in glottal airflow parameters according to oral contraceptive (OC) use. Subjects and Methods: The participants included 16 women, 20-24 years of age. Eight women were taking a triphasic OC; the remaining 8 women were not taking any form of oral contraception (NOC). All participants were recorded on days 7 and 14 of their menstrual cycle. Three repetitions of the sustained vowel /a/ were obtained using a circumferentially vented respiratory face mask connected to a wide-band pressure transducer. Measures of peak flow, minimum flow, alternating flow, fundamental frequency $\left(F_{0}\right)$ and relative sound pressure level were obtained. Results: A multivariate analysis of variance with sound pressure level as a covariate
\end{abstract}

M.G.R. is currently affiliated with the Department of Communication Sciences and Disorders, Valdosta State University, Valdosta, Ga., and L.F. with the Communication Disorders Program, Georgia State University, Atlanta, Ga., USA. Portions of this paper were presented at the American Speech-Language-Hearing Association Conventions, Chicago, III., USA, November 2003, and Philadelphia, Pa., USA, November 2004.

\begin{tabular}{ll}
\hline KARGER & ( 2007 S. Karger AG, Basel \\
Fax +4161306 1234 $34-7762 / 08 / 0601-0020 \$ 24.50 / 0$ \\
$\begin{array}{l}\text { E-Mail karger@karger.ch } \\
\text { www.karger.com }\end{array}$ & $\begin{array}{l}\text { Accessible online at: } \\
\text { www.karger.com/fpl }\end{array}$
\end{tabular}

revealed no significant effect of day of recording upon the dependent measures. As a group, the $\mathrm{OC}$ women exhibited significantly higher $F_{0}$, peak and alternating flow rates compared to the NOC women. Removal of data outliers from the OC women resulted in similar airflow rates for both groups. Conclusion: The findings from this preliminary study did not support the use of glottal airflow measures to distinguish $O C$ women from NOC women. Differences in $F_{0}$ findings may reflect hormonally mediated changes in laryngeal tissue and warrant further investigation. Copyright $\odot 2007$ S. Karger AG, Basel

\section{Introduction}

Prior studies have demonstrated that fluctuations in ovarian hormone levels during the menstrual cycle, e.g., estrogen and progesterone, may have a significant effect upon the voice [1-5]. Premenstrually-related voice changes include vocal fatigue, decreased intensity range, loss of harmonics and reduced frequency perturbation [1-3], which are associated with vocal fold edema, erythema and laryngeal joint stiffness $[1,4,5]$. During menstruation, an increased harmonics-to-noise ratio and increased vocal hoarseness have been reported, while ovulation is associated with greater frequency perturbation [5-6].

\footnotetext{
Mary Gorham-Rowan, $\mathrm{PhD}$

Department of Special Education and Communication Disorders

Valdosta State University, 1500 N. Patterson St.

Valdosta, GA 31698 (USA)

Tel. +1 229219 1321, Fax +1 229219 1335, E-Mail mmgorhamrowan@valdosta.edu
} 
The increased vibratory instability during ovulation may be related to alterations in neurotransmitter levels associated with hormonal flux, thus affecting laryngeal motor control [5].

More recent investigations concerning the influence of hormones upon the voice have focused on oral contraceptives (OCs). Currently available OCs appear to have a beneficial effect upon the voice as evidenced by lower perturbation values and decreased noise in the acoustic signal [7-12]. These data suggest that OCs exert a stabilizing influence upon vocal function. OCs are generally designed to prevent the release of certain hormones, thereby avoiding large fluctuations in hormone levels that would normally occur during the menstrual cycle. This stable hormonal environment appears to contribute to increased phonatory stability, possibly by reducing or eliminating hormonally mediated laryngeal tissue changes.

As noted by Amir and Biron-Shental [12], the available evidence indicates that hormonal fluctuations during the menstrual cycle may alter vocal fold regulation of vibration. Information concerning the effect of hormonal changes on vibratory control has been limited primarily to acoustic data. Additional information may be obtained by examining aerodynamic parameters associated with phonation. Specifically, parameters such as those obtained through inverse filtering, e.g., peak glottal airflow, minimum glottal airflow, alternating glottal airflow, etc., may provide insight concerning the extent to which menstrual cycle alterations in vocal fold tissue affect laryngeal airflow regulation. Such information would be useful in determining if vocal fold vibration is significantly affected by alterations in laryngeal tissue during menstruation, e.g., edema and/or erythema. Hence, the purpose of this study was to assess the impact of triphasic OC upon glottal airflow measures in young women.

\section{Methods}

\section{Participants}

A total of 16 women participated in the study. Eight women, 19-20 years of age, were taking a triphasic OC, including the brand names Ortho Tri-Cyclen (norgestimate/ethinyl estradiol) and Estrostep (norethindrone/ethinyl estradiol). The remaining 8 women, aged 19-24 years, were not taking any form of oral contraception. All participants demonstrated vocal quality within normal limits, as judged by a certified speech-language pathologist, and were free from allergies or colds on the days of testing per self-report. All participants reported a regular menstrual cycle of approximately 28 days.

Voice and Oral Contraceptives

\section{Procedures}

Voice recordings were collected in a soundproof booth using a circumferentially vented respiratory face mask [13] connected to a wide-band pressure transducer (PTW-1). The system was calibrated with a known airflow value $(500 \mathrm{l} / \mathrm{s}$ with a 2 -liter volume exchange) from a rotameter (MCU-4 calibration unit, Glottal Enterprises) prior to each recording session. Inverse filtering of the airflow signal was completed using TF32 [14] to yield a glottal airflow waveform $[13,15]$. All data were recorded and stored on a PCM Vetter data recorder coupled to a customized DAT recorder (SONY VDAT8).

Voice recordings were obtained during 2 points in the menstrual cycle: between days 6 and 8 , to correspond to the cessation of menstruation, and between days 13 and 15, to correspond to ovulation. Cessation of menstruation is generally associated with low hormone levels, while ovulation is generally related to changes in estrogen and progesterone levels [16]. Hence, vocal function may be differentially affected during these time frames. For each recording, the participants were asked to prolong the vowel /a/ 3 times at a comfortable pitch and loudness level for approximately $5 \mathrm{~s}$. The participants were instructed to maintain a steady loudness level across all trials. Vocal intensity levels were monitored visually via the display of an analog sound pressure level (SPL) monitor (FSPL-1, DFI Enterprises, Inc.). Trials involving excessive loudness were not included for analysis. The data were also checked following each attempt for negative minimum airflow values that would indicate possible air leakage from the facemask. Trials exhibiting such values were not included for analysis.

\section{Measurements}

The aerodynamic measurements of peak glottal airflow, minimum glottal airflow (DC flow) and alternating glottal airflow (AC flow) were derived from the glottal airflow waveform. Fundamental frequency $\left(\mathrm{F}_{0}\right)$ was also derived from the airflow waveform. The relative vocal intensity was determined using the average root mean square of the energy signal obtained from the vowel segment (CSL, Kay Elemetrics).

\section{Data Analysis}

For each trial of sustained vowel phonation, the middle $200 \mathrm{~ms}$ of phonation were hand-marked for analysis and analyzed using TF32. The mid-portion of the vowel segment was used for analysis in order to eliminate any onset/offset effects. Means and standard deviations (SD) were calculated across the 3 measured vowels for each subject for each dependent variable. Inter- and intrarater reliability data were obtained on $20 \%(n=3)$ of the data for each parameter and analyzed using the Pearson $r$ correlation coefficient measure. The intrarater reliability was high, ranging from $r=0.99$ to $r=1.00$. The inter-rater reliability was also high, ranging from $r=0.94$ to $r=0.99$.

An initial correlation analysis revealed that SPL was significantly correlated with peak flow $\left(\mathrm{r}^{2}=0.548, \mathrm{p}<0.001\right)$, DC flow $\left(r^{2}=0.405, p=0.024\right)$ and AC flow $\left(r^{2}=0.530, p=0.002\right)$. Since aerodynamic parameters may be influenced by changes in vocal intensity [17], a multivariate analysis of variance with SPL as the covariate was used to test the dependent variables for group differences according to OC use. The level of statistical significance was set a priori at $\mathrm{p}<0.05$. All statistical analyses were completed using SPSS 11.5. 
Table 1. Mean and standard deviation values for $\mathrm{F}_{0}$ and aerodynamic parameters for OC and NOC women

\begin{tabular}{|c|c|c|c|c|c|}
\hline & $\mathrm{F}_{0}, \mathrm{~Hz}$ & Peak flow, ml/s & DC flow, $\mathrm{ml} / \mathrm{s}$ & AC flow, $\mathrm{ml} / \mathrm{s}$ & SPL, dB \\
\hline \multicolumn{6}{|c|}{ NOC day 7} \\
\hline Mean & 208.74 & 231.30 & 108.80 & 152.50 & 54.73 \\
\hline SD & 24.19 & 45.80 & 31.37 & 32.40 & 4.99 \\
\hline \multicolumn{6}{|c|}{ NOC day 14} \\
\hline Mean & 206.36 & 227.50 & 90.00 & 145.00 & 55.78 \\
\hline SD & 21.76 & 43.67 & 28.78 & 29.76 & 2.28 \\
\hline \multicolumn{6}{|l|}{ NOC } \\
\hline Mean & 207.55 & 229.40 & 99.40 & 148.80 & 55.26 \\
\hline $\mathrm{SD}$ & 22.26 & 43.28 & 30.65 & 30.30 & 3.79 \\
\hline \multicolumn{6}{|l|}{ OC day 7} \\
\hline Mean & 232.06 & 292.50 & 121.30 & 195.00 & 54.69 \\
\hline $\mathrm{SD}$ & 16.45 & 99.53 & 49.70 & 71.51 & 6.14 \\
\hline \multicolumn{6}{|l|}{ OC day 14} \\
\hline Mean & 230.68 & 238.60 & 114.30 & 165.70 & 53.85 \\
\hline SD & 16.62 & 75.15 & 71.85 & 67.79 & 4.56 \\
\hline \multicolumn{6}{|l|}{$\mathrm{OC}$} \\
\hline Mean & 231.42 & 267.30 & 118.00 & 181.30 & 54.30 \\
\hline $\mathrm{SD}$ & 15.94 & 90.27 & 58.82 & 68.96 & 5.29 \\
\hline
\end{tabular}

\section{Results}

Group means and SD for the acoustic and aerodynamic data are presented in table 1 . The results of the multivariate analysis of variance revealed a significant effect of OC use upon the measures of peak flow $[\mathrm{F}(1,26)=4.922$, $\mathrm{p}=0.035]$ and AC flow $[\mathrm{F}(1,26)=5.940, \mathrm{p}=0.022]$ as well as $\mathrm{F}_{0}[\mathrm{~F}(1,26)=11.754, \mathrm{p}=0.002]$. As can be seen from table 1, the OC group exhibited greater airflow rates and a higher mean $\mathrm{F}_{0}$ compared to the NOC group. No significant effect of day of recording on any of the dependent measures was observed, as both groups of participants exhibited generally stable aerodynamic measures across the 2 measurement days. Likewise, there were no significant findings for the OC use by day of recording interaction.

\section{Discussion}

The present study sought to provide some insight into the effect of hormonal changes associated with the menstrual cycle on glottal airflow measures. The results of previous studies have demonstrated increased vocal stability among OC users as evidenced by reduced perturbation in the acoustic signal and an increase in the harmonic-to-noise ratio or signal-to-noise ratio [7-9, 11]. However, Amir and Biron-Shental [12] suggested that fluctuations in hormonal levels may affect vibratory control of the vocal folds. Additionally, Higgins and Saxman [5] proposed that the increase in perturbation observed during ovulation was due to neuromotor disruption of vibratory regulation.

The results of the present study revealed significant differences in selected glottal airflow parameters between the 2 groups of women. Specifically, women taking OCs exhibited greater peak and alternating flow rates compared to the women not taking OCs. One might suspect that differences in glottal airflow rates between the 2 groups of women may indicate differences in glottal configuration during phonation. However, closer inspection of the data revealed that while the majority of participants exhibited airflow rates within a small range (e.g., 18-25 ml/s for peak glottal airflow), 3 of the participants in the OC group exhibited notably higher airflow rates (e.g., $30-40 \mathrm{ml} / \mathrm{s}$ ). For 2 participants, this higher rate was observed on the first day of recording (day 7); for the third participant, the increase occurred on the second day of recording (day 14). Subsequent exclusion of these data resulted in no significant difference in airflow rates between the 2 groups. Hence, these findings do not support the use of airflow measures to assess the impact of OC use upon the voice. Furthermore, given that no data exist regarding the stability of airflow measures across multiple days of recording, it would not be prudent to use airflow measures at this 
time to measure changes in laryngeal function across the menstrual cycle.

In conjunction with the glottal airflow findings, significantly higher $\mathrm{F}_{0}$ levels were found for the $\mathrm{OC}$ women compared to the NOC group. Prior reports have yielded conflicting results concerning $\mathrm{OC}$ use and $\mathrm{F}_{0}$. Higher $\mathrm{F}_{0}$ levels have been reported near the time of ovulation in a small group of women [7] and in a larger, retrospective study in which the type of OC was not controlled [11]. However, other studies have found no significant effect of OC use upon $\mathrm{F}_{0}[8,9,18]$. Hence, it is possible that any $\mathrm{F}_{0}$ differences in this subject group may be due to nonhormonally related factors, as previously suggested [7], or even reflect sampling error. We are currently conducting a longitudinal study to further investigate OC use and vocal function.

The results of the present study did not demonstrate any significant effect of day of recording upon any of the parameters. This finding is consistent with other reports that the phases of the menstrual cycle have no effect upon $\mathrm{F}_{0}$ and frequency perturbation measures $[9,19]$. However, these findings conflict with previous data reported by Amir et al. [7] and Amir and Kishon-Rabin [9], who reported a significant interaction between $\mathrm{F}_{0}$ and time of measurement, as well as between frequency perturbation measurements (i.e., jitter, relative average perturbation and pitch period perturbation quotient) and time of measurement. They suggested that the observed differences relative to $\mathrm{F}_{0}$ and frequency perturbation were possibly due to the hormonal fluctuations associated with ovulation or to some other influential factor as yet unidentified. A possible reason for the differing findings is that Amir et al. [7] recorded their participants every 4 days throughout a menstrual cycle. In the present study, the timing of ovulation was an estimate based on the participants' reports of a regular menstrual cycle lasting approximately 28 days. It is therefore possible that ovulation did not consistently occur across the NOC group.
Future studies should include direct measurement of hormonal level from urine or serum blood samples in order to more clearly define the timing of ovulation.

It is also possible that the different results between these studies may relate to the extent to which hormonal fluctuations affected the respective participants. Abitbol et al. [1] reported that significant premenstrual changes in laryngeal appearance and function were not observed in all participants included in their study. That is, just as the degree to which women vary in experiencing physical and/or mental symptoms associated with premenstruation (i.e., bloating, weight gain, moodiness, irritability, etc.), women may differ in the extent to which they experience a 'vocal premenstrual syndrome'. This difference is likely related to the fact that hormonal levels may vary significantly between individual women, especially with regard to estrogen [20]. Hence, certain studies may report differing outcomes due in part to the composition of the participant groups or the specific hormonal characteristics associated with the menstrual phase during which testing takes place.

In conclusion, obtaining voice recordings during 2 points in the menstrual cycle did not yield findings that supported the use of airflow measures to examine hormonally mediated changes in laryngeal function in this preliminary investigation. However, the results of this study raise the question of whether $\mathrm{F}_{0}$ is affected by OC use. Given the conflicting reports regarding $\mathrm{F}_{0}$ and $\mathrm{OC}$ use, further studies should obtain voice recordings in conjunction with serum blood samples over several menstrual cycles. In addition, both monophasic and triphasic OCs should be examined separately in such a study to determine if the type of $\mathrm{OC}$ affects $\mathrm{F}_{0}$ differently. The inclusion of a rating system regarding the participants' perceptions of physical symptoms and voice quality during the menstrual cycle may also be desirable in future investigations.
References

Voice and Oral Contraceptives 
6 Brown WS, Rothman H: The menstrual cycle and its relationship to the highly stressed female voice; in Lawrence V (ed): Transcripts of the Ninth Symposium: Care of the Professional Voice. New York, Voice Foundation, 1985, pp 114-123.

7 Amir O, Kishon-Rabin L, Muchnik C: The effect of oral contraceptives on voice: preliminary observations. J Voice 2002;16:267272.

-8 Amir O, Biron-Shental T, Muchnik C, Kishon-Rabin L: Do oral contraceptives improve vocal quality? Limited trial on lowdose formulations. Obstet Gynecol 2003;101: 773-777.

9 Amir O, Kishon-Rabin L: Association between birth control pills and voice quality. Laryngoscope 2004;114:1021-1026.
10 Langford A, Gorham-Rowan M: Acoustic measures of young women's voices associated with oral contraceptive use. Paper presented at the American Speech-LanguageHearing Association Convention, Atlanta, November 2002.

11 Gorham-Rowan MM: Acoustic measures of vocal stability during different speech tasks in young women using oral contraceptives: a retrospective study. Eur J Contracept Reprod Health Care 2004;9:166-172.

2 Amir O, Biron-Shental T: The impact of hormonal fluctuations on female vocal folds. Curr Opin Otolaryngol Head Neck Surg 2004;12:180-184.

13 Rothenberg MR: Measurement of airflow in speech. J Speech Hear Res 1977;20:155-176.

14 Milenkovic P: TF32. Madison, University of Wisconsin, 2001.

15 Rothenberg MR: A new inverse-filtering technique for deriving glottal air flow waveform during voicing. J Acoust Soc Am 1973; 53:1632-1645.
16 Greenspan FS, Strewler GJ: Basic and Clinical Endocrinology, ed 5. Stamford, Appleton \& Lange, 1997, pp 441-444.

17 Holmberg EB, Hillman RE, Perkell JS: Glottal airflow and transglottal air pressure measurements for male and female speakers in soft, normal, and loud voice. J Acoust Soc Am 1988;84:511-529.

18 Gorham-Rowan M, Langford A, Corrigan K, Snyder B: Vocal pitch levels during connected speech associated with oral contraceptive use. J Obstet Gynaecol 2004;24:284-286.

19 Silverman EM, Zimmer CH: Effect of the menstrual cycle on voice quality. Arch Otolaryngol 1978;104:7-10.

20 Johansson ED, Wide L, Gemzell C: Luteinizing hormone (LH) and progesterone in plasma and LH and oestrogens in urine during 42 normal menstrual cycles. Acta Endocrinol (Copenh) 1971;68:502-512. 